Int. J. Electrochem. Sci., 12 (2017) $8591-8598$

\title{
Structure and Electrochemical Properties of Hierarchically Porous Silicon Film Prepared with the Combination of Magnetron Sputtering Deposition and Metal-Assisted Chemical Etching
}

Yan Zhao ${ }^{1,2}$, Zhengjun Liu' ${ }^{1}$, Chunyong Liang ${ }^{1,2, *}$, M. Yu. Maximov ${ }^{4}$, Baoxi Liu ${ }^{1,2}$, Junming Wang ${ }^{3}$, Fuxing Yin ${ }^{1,2}$

${ }^{1}$ School of Material Science \& Engineering, Research Institute for Energy Equipment Materials, Hebei University of Technology, Tianjin 300130, China

${ }^{2}$ Tianjin Key Laboratory of Materials Laminating Fabrication and Interface Control Technology, Hebei University of Technology, Tianjin 300130, China

${ }^{3}$ Synergy Innovation Institute of GDUT, Heyuan, Guangdong Province, China

${ }^{4}$ Peter the Great Saint-Petersburg Polytechnic University, Saint-Petersburg, 195221, Russia

*E-mail: liangcy_hebut@outlook.com

doi: $10.20964 / 2017.09 .16$

Received: 5 February 2017 / Accepted: 22 June 2017 / Published: 13 August 2017

A novel hierarchically porous silicon film on $\mathrm{Cu}$ foil was fabricated by employing the combination of magnetron sputtering deposition and metal-assisted chemical etching technology. The as-prepared porous Si film were directly used as working electrodes without adding of binder or electron conductive agent, which exhibited high specific capacities and stable cyclability. Specifically, a high initial discharge capacity of $1976 \mathrm{mAh} \mathrm{g}^{-1}$ is attained at a current density of $300 \mathrm{~mA} \mathrm{~g}^{-1}$ and a stable discharge capacity of $1629 \mathrm{mAh} \mathrm{g}^{-1}$ obtained after 100 cycles. This superior electrochemical properties could be ascribed to the unique hierarchically porous structure, effectively buffering volume changes during the charge/discharge process.

Keywords: Hierarchically Porous Si film, Metal-assisted chemical etching, Magnetron sputtering deposition, Lithium-ion battery.

\section{$\underline{\text { FULL TEXT }}$}

(C) 2017 The Authors. Published by ESG (www.electrochemsci.org). This article is an open access article distributed under the terms and conditions of the Creative Commons Attribution license (http://creativecommons.org/licenses/by/4.0/). 